University of Nebraska - Lincoln

DigitalCommons@University of Nebraska - Lincoln

7-1991

\title{
Survivorship and Recruitment in a Long-lived Prairie Perennial, Ipomoea leptophylla (Convolvulaceae)
}

Kathleen H. Keeler

University of Nebraska - Lincoln, kkeeler1@unl.edu

Follow this and additional works at: https://digitalcommons.unl.edu/bioscifacpub

Keeler, Kathleen H., "Survivorship and Recruitment in a Long-lived Prairie Perennial, Ipomoea leptophylla (Convolvulaceae)" (1991). Faculty Publications in the Biological Sciences. 287.

https://digitalcommons.unl.edu/bioscifacpub/287

This Article is brought to you for free and open access by the Papers in the Biological Sciences at DigitalCommons@University of Nebraska - Lincoln. It has been accepted for inclusion in Faculty Publications in the Biological Sciences by an authorized administrator of DigitalCommons@University of Nebraska - Lincoln. 


\title{
Survivorship and Recruitment in a Long-lived Prairie Perennial, Ipomoea leptophylla (Convolvulaceae)
}

\author{
KATHLEEN H. KEELER \\ School of Biological Sciences, University of Nebraska-Lincoln, Lincoln 68588-0343
}

\begin{abstract}
Little is known of the lifespans of herbaceous plants, especially in grasslands, although this information is basic to understanding the dynamics of species and ecosystems. Permanently marked plants of the bush morning glory, Ipomoea leptophylla (Convolvulaceae), in Nebraska sandhills prairie were censused annually from 1979-1989. While the average annual death rate was 2.6 per 100 , virtually all the mortality was among smaller and probably younger plants. Recruitment varied greatly among years. Of plants of known age, the median age at first flowering was 6 yr. After 9 yr 30\% had never flowered. Larger size classes flowered more frequently than smaller mature plants and were more likely to mature seeds successfully. For this polycarpic nonrhizomatous herb, a generation is probably over 2 decades and some plants may live more than a century. As a result, environmental variation on the scale of even the Great Drought may be a passing interval of minor impact on lifetime fecundity for established adults, although until extreme years have been observed this cannot be proven.
\end{abstract}

\section{INTRODUCTION}

It is difficult to study the dynamics of plant species in which the individuals live a substantial proportion of a human lifespan. Long-lived populations may not show the same dynamics or relation to environmental variation as shorter-lived species; thus we cannot hope to understand the ecology of long-lived species by studying annuals or short-lived perennials. Certainly adaptations to mitigate short-term, even annual, variation, could be quite different in species that live for a few years vs. those that live for decades or centuries. Longevities of plants in grassland ecosystems are especially difficult to study because few species produce woody structures that can be aged retrospectively. Thus, while most prairie plants appear to be long-lived (Weaver, 1965; Platt, 1975; Reichman, 1987), there are few data on the dynamics of these species.

This paper reports a 10 -yr study of survivorship and recruitment in two populations of Ipomoea leptophylla, a long-lived native morning glory of the high plains. This ongoing study was initiated (1) to determine the actual survivorship and fecundities of a long-lived perennial herb and (2) to evaluate whether short-term observations can adequately describe the dynamics of this long-lived species.

Ipomoea leptophylla Torr., the bush morning glory, is a deep-rooted perennial that grows in sandy sites from South Dakota to Colorado, Oklahoma to New Mexico (Austin, 1986). The plants have narrow leaves and a bushy herbaceous habit. A large plant's aboveground biomass can reach $3 \mathrm{~kg}$ dry weight, and may cover $4 \mathrm{sq} \mathrm{m}$ of the soil surface. Belowground, I. leptophylla develops a large root tuber, generally at least $0.5 \mathrm{~m}$ below the soil surface (Weaver, 1958). These tubers, presumably for water and food storage, can grow to be 0.5 $\mathrm{m}$ in diam and weigh in excess of $6 \mathrm{~kg}$ dry weight (Weaver, 1965; Keeler, 1980b). The plant does not reproduce vegetatively. A single tuber may have as many as six aboveground shoots, but these emerge from the ground within an area of $0.25 \mathrm{sq} \mathrm{m}$.

In western Nebraska, plants emerge from the soil in late June, with preformed buds that open early in July. In good flowering years, additional buds are initiated as the plant grows and flowering continues into August. The seeds are large $(0.1 \mathrm{~g})$ (Keeler, 1980b). At the end of the growing season, the stems absciss at ground level, and the plant top, carrying 
the opening capsules with (if fully pollinated) four seeds, blow across open shortgrass or sandhills prairie, scattering seeds.

\section{SiTES}

Plants were studied in sandhills prairie of western Nebraska. For a description of sandhills prairie, see Pool (1914) or Tolstead (1942). The major marked population was at Arapaho Prairie, Arthur Co., a two-section ( 526 ha) prairie reserve owned by The Nature Conservancy and managed by the School of Biological Sciences, U. Nebraska-Lincoln (Keeler et al., 1980). Grazing by cattle was discontinued in January 1977. In August 1979, all Ipomoea leptophylla plants within a $180 \times 180 \mathrm{~m}$ grid were marked and mapped. The grid, established for lizard demographic studies, is on a W-facing slope, ca. $20 \mathrm{~m}$ above the valley floor, and includes slope and ridge vegetation, plus washes (Keeler et al., 1980). A full description of the vegetation in the grid in 1978 is given in Jones and Droge (1980) and a map indicating changes appears in Jones and Ballinger (1985). The morning glory population was censused annually in late August or early September, except for 1981 when it was studied in late June.

The second marked population was in Keith Co., just $\mathrm{E}$ of Lake McConaughy. The Ipomoea leptophylla population studied was at the base of Kingsley Dam, a 157-ft (48 m) earthen dam completed in 1941 (Central Nebraska Public Power District, CNPPD, 1965). The plant community at the Kingsley Dam site was disturbed sandhills prairie: generally typical prairie vegetation except for a substantial stand of smooth brome (Bromus inermis). The site is part of the Nebraska Public Power District's buffer zone around the dam and is neither grazed nor burned. It is close to popular fishing areas, but the particular site chosen for the I. leptophylla study receives very little human visitation. Because of its position at the base of a huge earthen dam, more than $45 \mathrm{~m}$ below the waterline, water is probably not limiting to the Kingsley Dam population. Certainly, the plants flowered in the record dry June of 1978, unlike most populations in the region (Keeler, 1980b). The plants were permanently marked in 1977 and followed annually through 1981 . The site at that time was irregularly shaped, approximately $2100 \mathrm{~m}^{2}$. In August 1989, the site was resurveyed. At that time, GNPPD had pushed uprooted trees and brush onto the northern half of the site with heavy equipment, destroying many of the plants there. Consequently the observations in 1989 were confined to the undisturbed southern half of the site, approximately $800 \mathrm{~m}^{2}$.

Supplemental observations were made on plants in sandhills and shortgrass prairie in Arthur and Keith counties, Nebraska.

\section{METHODS}

During the study 320 plants were marked with permanent aluminum tags held in the ground by large nails.

Size categories were established for the plants, based on aboveground size. In the field, plants were classified subjectively as tiny, tiny-small, small, small-medium, medium, medium-large, large and huge. For analysis, these were combined into four categories: tiny, small, medium and large, with the intermediate categories assigned to the smaller size class (e.g., small-medium was combined with small). To determine absolute size ranges, plants from outside the plot were assigned size categories, dug up, dried and weighed. These studies indicated that tiny plants were smaller than $10 \mathrm{~cm}$ long aboveground and weighed less than $20 \mathrm{~g}$ dry weight, root tuber included. Small plants were between 10 and $40 \mathrm{~cm}$ canopy diam with dry weight $20-80 \mathrm{~g}$. Medium plants were between 40 and $75 \mathrm{~cm}$ aboveground diam and weighed $50-400 \mathrm{~g}$. Large plants were over $75 \mathrm{~cm}$ in diam and had dry weights in 
excess of $400 \mathrm{~g}$. The upper end of "large" was very much greater than the lower end, but these plants were very few and did not differ from other large plants in their behavior, e.g., all survived the entire period, so are included in "large."

Whether the plant had attempted to flower was noted, to monitor reproductive effort and, in particular, age or size at first flowering. Flower buds are positioned differently than leaves and leave a distinctive scar. Plants not bearing reproductive tissue at the time of the census were searched for scars that indicated an attempt at reproduction.

In the first years of the study, the numbers of buds, flowers, green fruit and ripe (brown) fruit produced were counted. However, since seeds mature at different dates, no single census could assure the green fruit would actually mature, or that fruits that had already dehisced were healthy. Ipomoea leptophylla aborts unhealthy buds and unpollinated or damaged green fruit, but not seeds on which the seed coat has formed (pers. observ.). The bruchid beetle Megacerus discoidus (Say) infests from $0-100 \%$ of the seeds of a plant (Keeler, 1980b). The seeds could not be collected to determine presence of bruchids without affecting, to an unknown degree, the dynamics of the population, so I chose to estimate these parameters in order to follow natural recruitment. Given the problems with estimating actual seed production, counts of the number of buds, flowers, green fruit and ripe fruit were revised to use the categories: none, few ( $<10$ flowers on fruit and the plant), some (10-20 flowers and fruit) and many $(>20)$. These data are presented in only a skeletal fashion since the uncertainties of a short-term census and the concealed bruchids reduce the sensitivity of the data collected. These observations are summarized as to whether or not the plant (1) attempted flowering; (2) was likely to have matured at least one healthy seed (if ripe capsules were observed or if there were at least "some" buds, flowers or green fruit, the plant was recorded as having matured at least one seed), and (3) whether the plant had an outstanding seed crop ("many" green fruit or ripe capsules).

Data on reproductive effort and success were compared to plant size using analysis of variance (SAS glm procedure, SAS, 1988) and the chi-square statistic (Sokal and Rohlf, 1969) in order to test the relationship of age, size and year to flowering, the age or size required for sexual maturity and the likelihood that a plant would mature one or many seeds.

Death rate estimates require accurate determination of the year of death. Since the plants can survive underground without emerging (see below), $1 \mathrm{yr}$ of finding the permanent tag but no plant was not considered adequate evidence of death: plants were not considered dead unless they were absent for 3 consecutive yr. Death was then assigned to the 1 st yr in which the plant failed to appear.

Year-specific death rates were calculated by dividing the number dying during the year by the number alive at the beginning of the year: since five plants died during 1983 having been seen in 1983 but not thereafter, and the population size, before deaths, in 1983 was 159, the death rate for 1983 was calculated as 0.031 (Table 1).

Size-specific death rates are harder to determine because of the need to quantify the number of years lived by plants of a certain size in comparison to number of deaths at that size. For example, a tiny plant first seen in 1980 that died in 1984 provided $3 \mathrm{yr}$ in which the plant survived and 1 in which it died, while another tiny plant, found the same year, that died in 1986 provides $5 \mathrm{yr}$ of survival and 1 in which it died. To calculate size-specific death rates, the number of years of survival were added before taking a mean, so that, for the example above, the two tiny plants gave two deaths in $10 \mathrm{yr}$ of observations or a rate of 0.2 deaths per plant-yr.

The accuracy of calculations of recruitment rates depends upon finding new plants in the year they germinate, or finding all plants at an identical age. There is no way to 


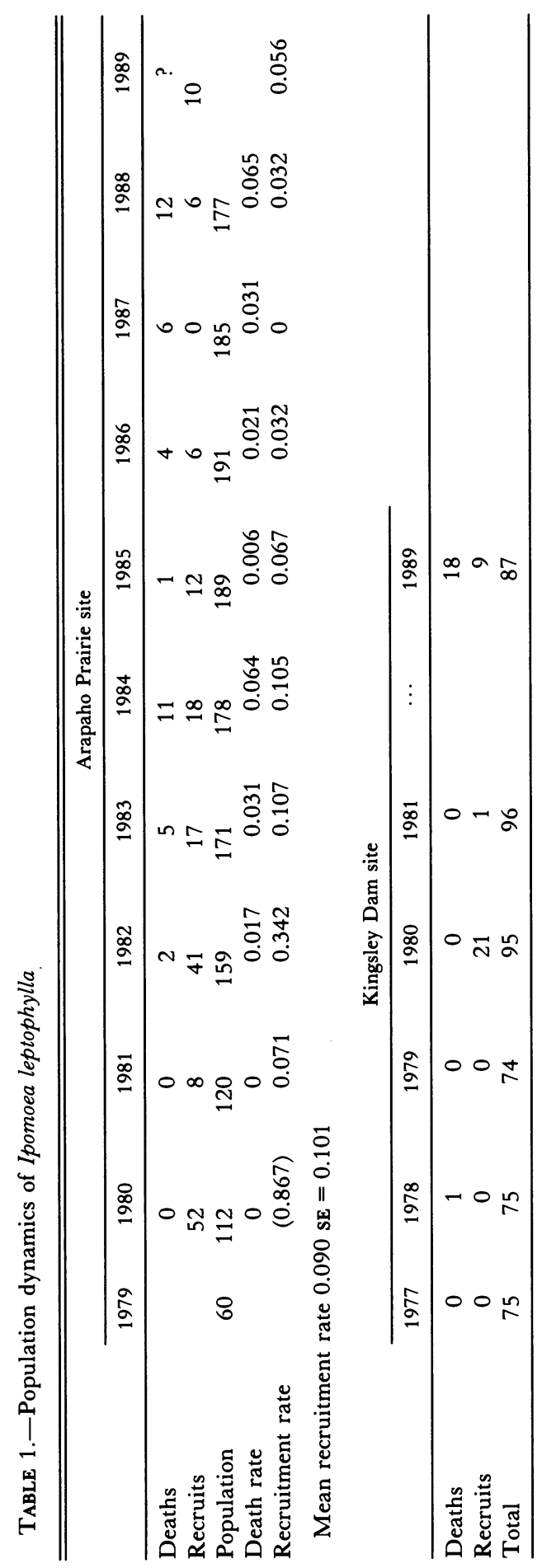




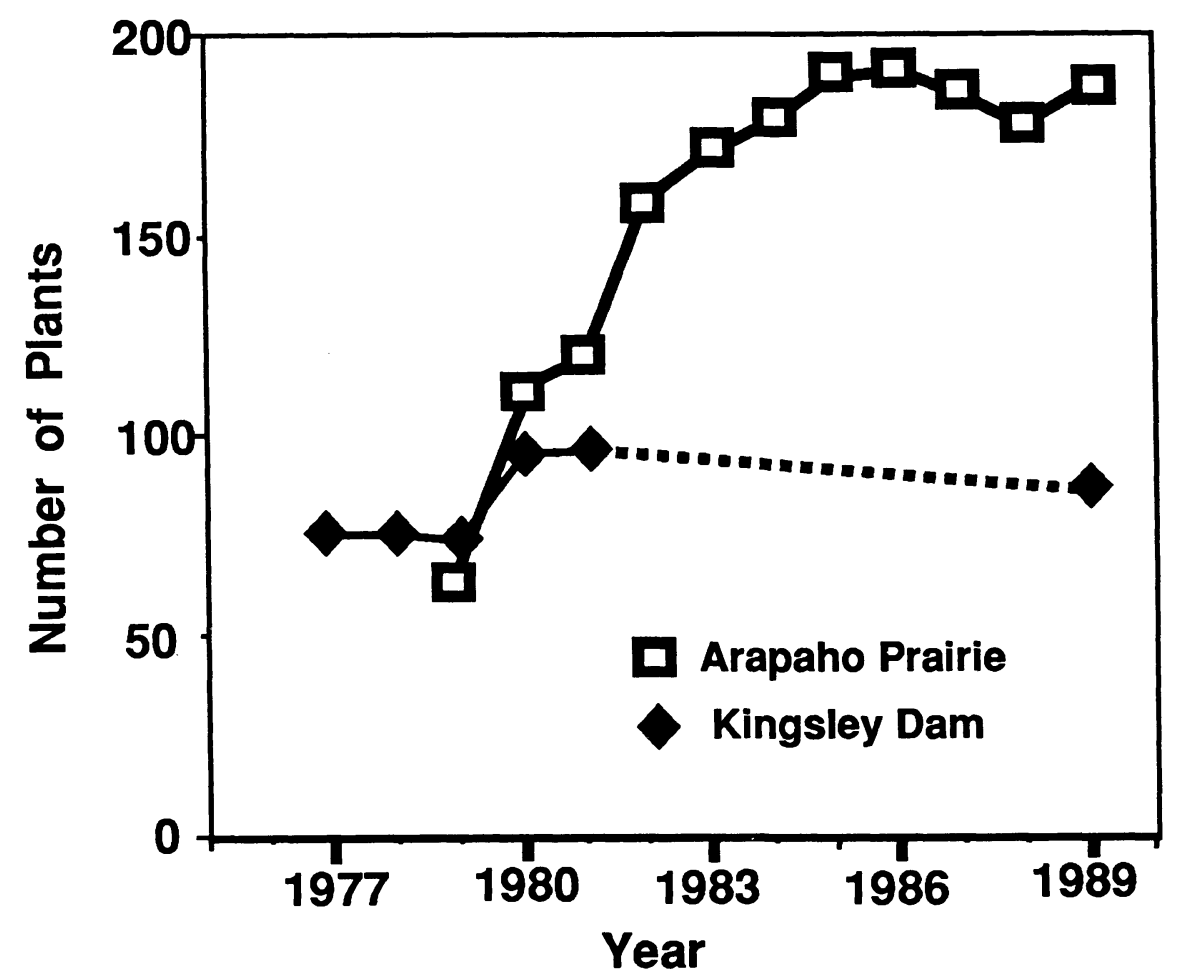

Fig. 1.-Changes in total population of Ipomoea leptophylla at Arapaho Prairie (open squares) and Kingsley Dam (dark diamonds)

guarantee that in a study of this sort, although each plot was searched for 16-25 h each year.

Mean recruitment was calculated by dividing population size of the previous summer into the number added to the population the next year. The recruitment rate for 1982 was 0.34 because 41 new individuals were added to a population that in 1981 was 120 (Table 1).

Totals in the different analyses (Tables 1-5, Figs. 1, 4) vary because for some purposes a plant with some missing information had to be deleted, while for other analyses it could be partially or totally included.

Identification of the fungus found causing damage to some plants (see below) was by L. V. Coziahr, Department of Plant Pathology, U. Nebraska-Lincoln; bruchid identification was by C. D. Johnson, Northern Arizona University (Keeler, 1980b).

\section{RESULTS}

The Arapaho Prairie population represents a sandhills prairie in good condition, although the cessation of grazing was associated with an increase in Ipomoea leptophylla density (Table 1, Fig. 1). The Kingsley Dam population, although in sandhills prairie, must have been established after the Dam was completed. This Ipomoea population is much denser and showed little change in number during the period observed (Table 1, Fig. 1). Data are described in detail for Arapaho Prairie and presented more briefly for Kingsley Dam. The site conditions and population dynamics offer a contrast which is not the subject of this 
TABLE 2.-Size-class transitions in Ipomoea leptophylla at Arapaho Prairie

\begin{tabular}{|c|c|c|c|c|c|}
\hline \multirow[b]{2}{*}{ Initial size } & \multicolumn{4}{|c|}{ Final size } & \multirow[b]{2}{*}{ Total } \\
\hline & Tiny & Small & Medium & Large & \\
\hline \multicolumn{6}{|c|}{10 Years of observations (original cohort) } \\
\hline Tiny & 7 & 10 & 3 & 0 & 20 \\
\hline Small & 1 & 13 & 21 & 7 & 42 \\
\hline Medium & 0 & 2 & 3 & 14 & 19 \\
\hline Large & 0 & 0 & 1 & 3 & 4 \\
\hline Died & 2 & 5 & 1 & 0 & 8 \\
\hline \multicolumn{6}{|c|}{ 5-9 Years of observations (cohorts from 1980-1984) } \\
\hline Tiny & 20 & 32 & 1 & 0 & 53 \\
\hline Small & 4 & 29 & 13 & 1 & 47 \\
\hline Medium & 0 & 0 & 2 & 0 & 2 \\
\hline Large & 0 & 0 & 0 & 0 & 0 \\
\hline Died & 7 & 3 & 1 & 0 & 14 \\
\hline \multicolumn{6}{|c|}{ Annual transitions } \\
\hline Year 0 & \multicolumn{4}{|c|}{ Year 1} & \\
\hline Tiny & 213 & 91 & 1 & 0 & 304 \\
\hline Small & 56 & 430 & 2 & 0 & 488 \\
\hline Medium & 4 & 36 & 186 & 57 & 283 \\
\hline Large & 0 & 0 & 19 & 82 & 101 \\
\hline
\end{tabular}

study. The similarities of individual survivorships, despite the population differences, reinforce the generality of the findings for life expectancy of this plant; the Kingsley Dam site despite typical sandhills prairie soil and plant community, showed an excess of introduced species and, being below the earthen dam, was unusually moist. Arapaho Prairie is considered typical natural habitat for the plant.

\section{ARAPAHO PRAIRIE POPULATION}

Population and individual growth. - Total population size at Arapaho Prairie rose in 19791983 but has been relatively stable since 1984 (Table 1, Fig. 1). The initial survey in 1979 located 60 plants within the $180 \times 180 \mathrm{~m}$ grid. During the study, 160 plants were added and 41 died. The total population reached a maximum of 191 in 1985 (Table 1).

Plants tended to remain in the same size class for several years (Table 2). Of size class transitions during a decade for plants first observed in 1979, 28\% (26 of 93) remained the same size for the decade. Most $(45,48.4 \%)$ increased by a single size class and none increased three size classes (e.g., from tiny to large). For plants of known age the pattern is similar, although with the shorter time interval, there is less change. Single-year transitions show a similar pattern. Thus, plants increased in size slowly, with a third of the population remaining in the same size class for the decade of observation.

Decreases in size occurred. Occasionally a medium plant decreased to small one year and was dead the next. More frequently a sudden size decrease was followed by rapid recovery to previous size. Net decreases occurred in eight of the 187 plants observed, excluding those known to have died.

All available single-year size transitions were used to generate a stable size distribution. 


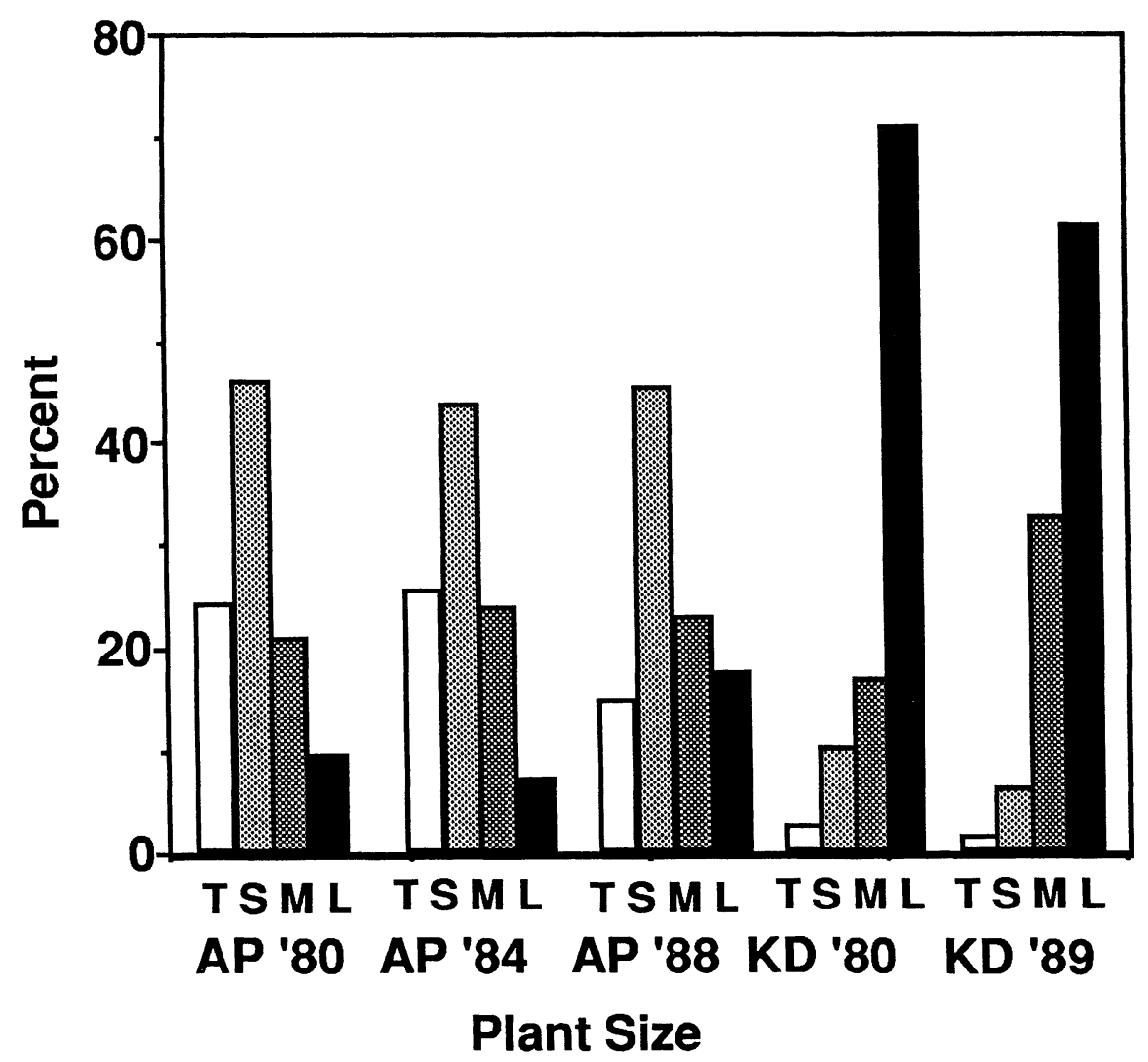

FIG. 2.-Size distribution of Ipomoea leptophylla plants, as percentages. From left to right Arapaho Prairie 1980, 1984, 1989, Kingsley Dam 1980, 1989. Size classes are tiny, small, medium and large (see text)

The frequency of each size transition was determined and used to establish a transition matrix (Table 2). To include the seed stage, values for seed production were estimated from mean annual seed production of each size class (see below). The average recruitment is estimated as 0.089 . Repeated iteration of the matrix produced a stable size distribution of approximately $5 \%$ tiny, $5 \%$ small, $32 \%$ medium and $49 \%$ large. This is a very much older population than current size distribution at Arapaho Prairie (Table 2, Fig. 2) although the 1989 size distribution is more similar to the stable size distribution than the 1979 size distribution. The stable size distribution projected for Arapaho is more similar to the Kingsley Dam population's size distribution than Arapaho Prairie at any time during the study (see below).

Plants can remain underground for more than a year without dying. Six cases of plants that were not found one year but reappeared the next were observed, while two other plants reappeared after 2 yr's absence. No plants reappeared after 3 yr's absence. Of the plants not appearing for 1 or $2 \mathrm{yr}$ four were tiny, three small and one medium. The medium plant was classified as small the year it returned. Plants were not disturbed to establish death, but rather followed for several years after they were last seen alive. 


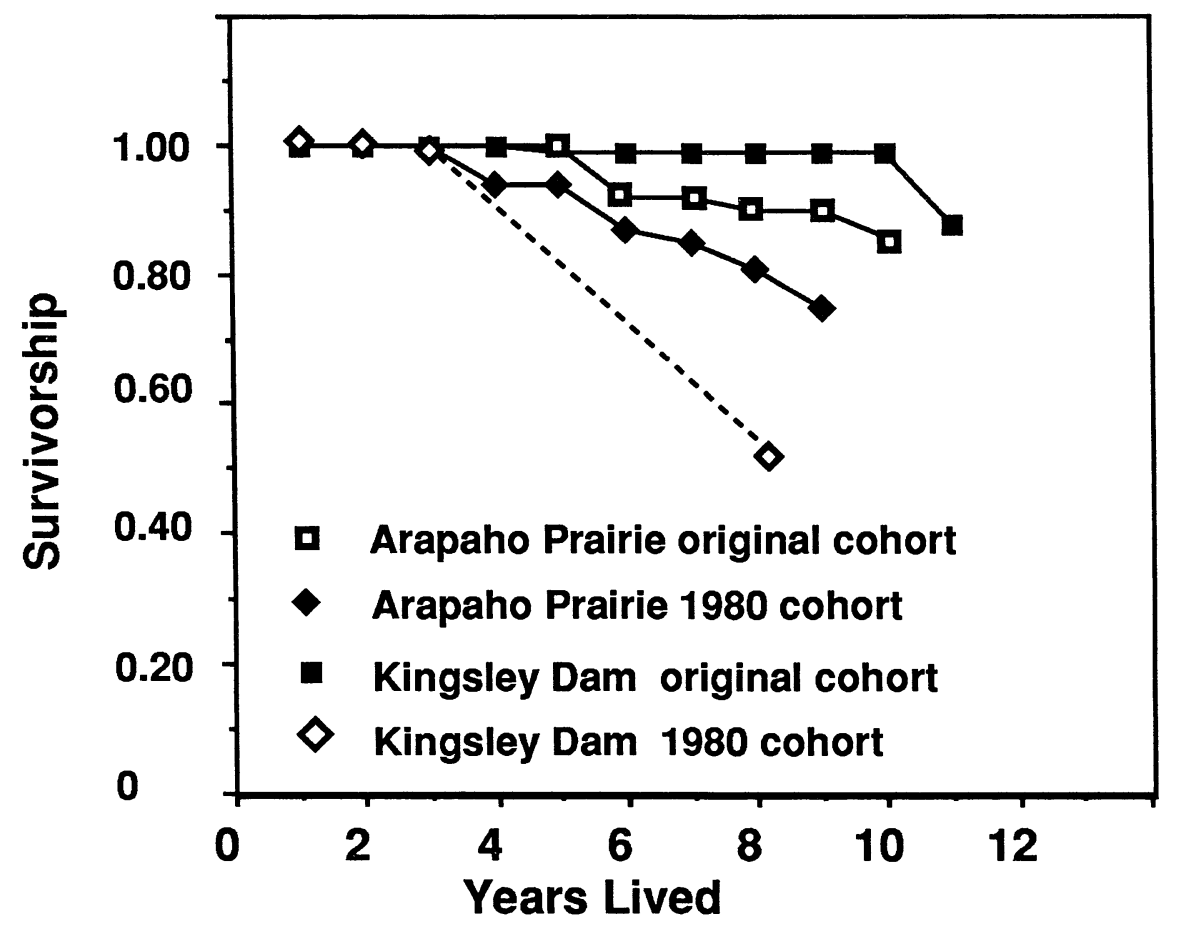

Fig. 3.-Comparison of Arapaho Prairie and Kingsley Dam survivorships. Plants present at Arapaho Prairie in 1979 (open squares), plants added at Arapaho Prairie 1980-1989 (dark diamonds), plants marked at Kingsley Dam in 1977 (dark squares), and plants added at Kingsley Dam in 1980 (open diamonds)

The size distribution from 1980 was compared to those in 1984 and 1988 (Fig. 2). These distributions are significantly different at the $2.5 \%$ level (chi-square $=14.49,0.025>\mathrm{P}>$ $0.01, \mathrm{df}=6$ ) due primarily to differences in the large size class.

In general Ipomoea leptophylla is a sparse plant (sensu Rabinowitz, 1981), making up less than $1 \%$ of cover and occurring in a frequency of ca. 0.01 [i.e., present in fewer than $1,1 / 4 \mathrm{~m}^{2}$-quadrat in 100 in sandhills prairie (Keeler 1980a, b; Barnes and Harrison, 1982)]. Consequently the increases in the early 1980 s would not be expected to continue for long, and indeed the plot appears to have stabilized at a density of about 180 plants per 38,400 $\mathrm{m}^{2}$. The increase seen may be a response to temporary changes, presumably caused by the removal of cattle.

Mortality. - Few plants died, and the causes of mortality were difficult to determine. Two plants, one small and one tiny, died after falling into the sandy wash upon whose rim they had been growing, presumably during erosion during a storm. Seven others (one tiny and six small when last seen) may have died of burial or root damage by pocket gophers, since gopher digging recurrently buried the plants' permanent tags. Several of the large plants were recurrently attacked by a fungus (Albugo ipomoea-panduratae, a white rust of the Oomycetes; Brown and Brotzman, 1982). Its most obvious effect is severely stunted stalks, often as they emerge from the ground, so that a plant of four or five stalks produces healthy 
TABLE 3.-Survivorships of Ipomoea leptophylla at Arapaho Prairie by year. A plant is counted in the year it was "last seen in." Relative survivorship: the original cohort contains the plants present when the population was first surveyed and therefore represents many size classes. Subsequent cohorts are even-aged (see text for comments)

\begin{tabular}{lccccccccccc}
\hline & & \multicolumn{10}{c}{ Year } \\
\cline { 3 - 12 } Cohort & $\mathrm{n}$ & 1979 & 1980 & 1981 & 1982 & 1983 & 1984 & 1985 & 1986 & 1987 & 1988 \\
\hline Original & 60 & 1.00 & 1.00 & 1.00 & 1.00 & 1.00 & 0.92 & 0.92 & 0.90 & 0.90 & 0.86 \\
1980 & 52 & $\mathrm{x}$ & 1.00 & 1.00 & 1.00 & 0.94 & 0.94 & 0.87 & 0.85 & 0.81 & 0.75 \\
1981 & 8 & & $\mathrm{x}$ & 1.00 & 0.88 & 0.75 & 0.75 & 0.75 & 0.75 & 0.62 & 0.62 \\
1982 & 41 & & & $\mathrm{x}$ & 1.00 & 0.98 & 0.95 & 0.95 & 0.88 & 0.85 & 0.83 \\
1983 & 17 & & & & $\mathrm{x}$ & 1.00 & 0.94 & 0.88 & 0.88 & 0.82 & 0.71 \\
1984 & 18 & & & & & $\mathrm{x}$ & 1.00 & 1.00 & 1.00 & 1.00 & 0.94 \\
1985 & 12 & & & & & & $\mathrm{x}$ & 1.00 & 1.00 & 0.92 & 0.75 \\
1986 & 6 & & & & & & & $\mathrm{x}$ & 1.00 & 1.00 & 0.67 \\
1987 & 0 & & & & & & & & $\mathbf{x}$ & 0 & 0 \\
1988 & 6 & & & & & & & & & $\mathbf{x}$ & 1.00 \\
& & & & & & & & & & & $\mathbf{x}$ \\
\hline
\end{tabular}

leaves on one or two stalks, the others being drastically dwarfed. Despite loss of a sizable percentage of potential photosynthetic tissue year after year, these large plants are still surviving and can still be described as large. One small plant that died as a "tiny" in 1985 was observed with fungal symptoms in 1982. Involvement of Albugo in other deaths is unknown. For the vast majority of the deaths, 27 (16 tiny, 9 small, and 2 medium at the time of death), no cause can be ascribed.

Of the 221 plants seen on Arapaho Prairie, 41 died (Table 1). This is a mean annual death rate of $2.6 \%(\mathrm{SE}=2.47)$. If it is assumed that the population neither increases nor decreases and every plant has the same lifespan, then individual lifespans should be $38 \mathrm{yr}$ $(261 / 100)$. While this is clearly an underestimate (see Table 3,4$)$ it gives an idea of the dynamics of the species.

Death rates varied with size. Plants in the categories tiny and small had the highest death rates. No "large" plants died during $10 \mathrm{yr}$ of observations. The death rates per 100 plants per year of original cohort (where age is not known) and of each year's cohorts (where age is known) were calculated. Using the initial size of the plant, the mortality of tiny and small

TABLE 4.- Size-specific death rates of Arapaho Prairie population. Totals differ from Tables 1-3 because of omission of problem cases

\begin{tabular}{|c|c|c|c|c|}
\hline \multirow[b]{2}{*}{ Original size: } & \multicolumn{4}{|c|}{ Number (\% of size class which died) } \\
\hline & Tiny & Small & Medium & Large \\
\hline Original cohort (1979-80) & 29 & 51 & 20 & 7 \\
\hline died since 1979 & $11(38)$ & $6(12)$ & $1(5)$ & $0(0)$ \\
\hline First seen $1981-1986$ & 47 & 61 & 3 & 0 \\
\hline died & $12(26)$ & $10(16)$ & $0(0)$ & \\
\hline $\begin{array}{l}\text { First seen } 1987 \\
\text { died }\end{array}$ & 0 & 0 & & \\
\hline First seen 1988 & 3 & 3 & & \\
\hline died (tentative) & $1(33)$ & $1(33)$ & & \\
\hline
\end{tabular}




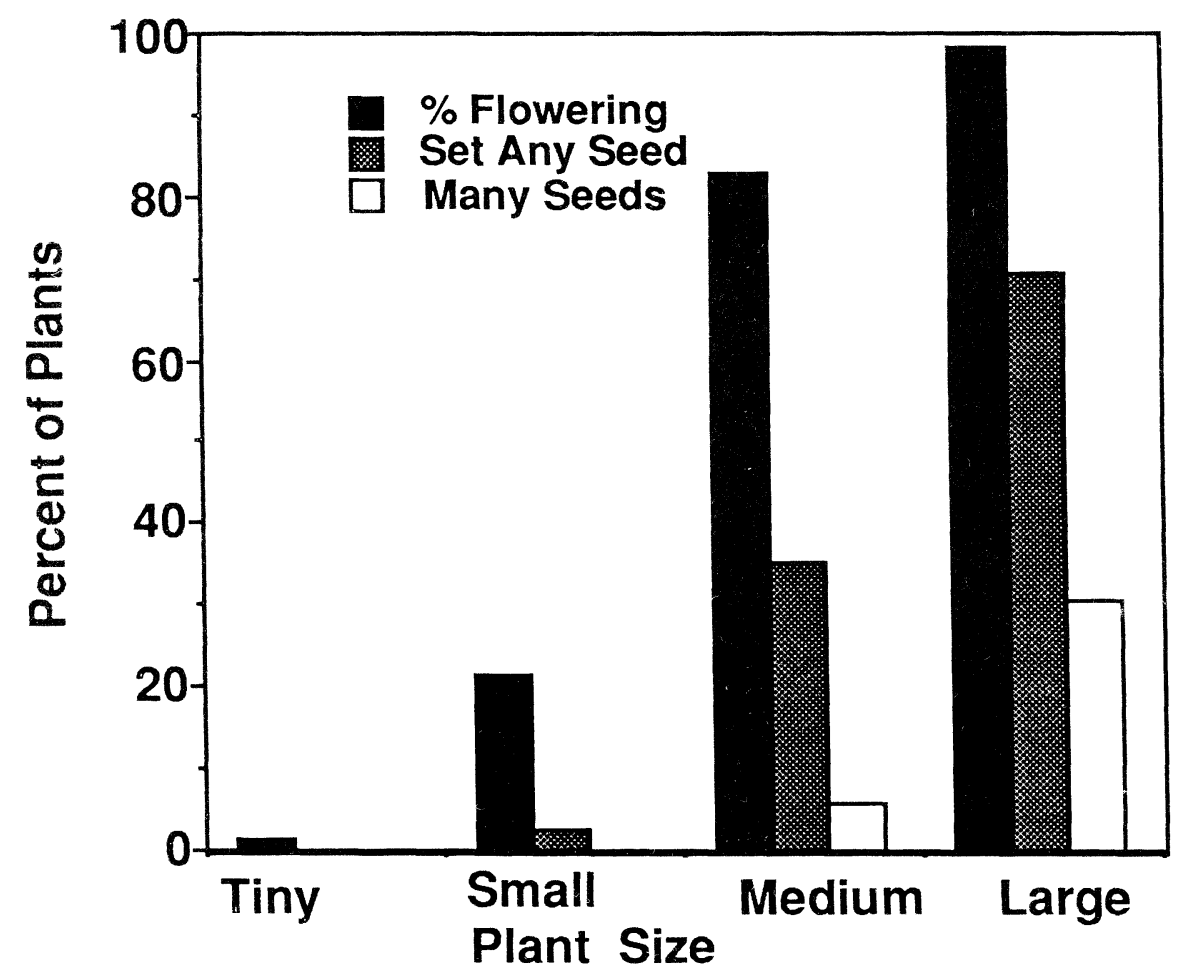

FIG. 4.-Relative flowering success of different size classes at Arapaho Prairie. See text for details

plants was $0-60 \%$ and for medium and large plants it was $0-5 \%$ (Table 4 ). These figures change only trivially if the size at death is used.

Age-specific death rates can be determined for ages 0-9. There were 42 tiny and 49 small plants first seen in 1981 or thereafter: $30.9 \%$ of tiny plants and $12.2 \%$ of small plants died (Table 4), but approximately $80 \%$ were alive after 6 yr (Fig. 4 ).

Age-specific survivorships were determined for ages 1 to 8 . Since $3 \mathrm{yr}$ are required to establish death, solid data is available only for age classes 1-8. Combining cohorts, survivorships of plants of known age are found to be $0.97,0.93,0.93$ and 0.88 for the 1 st $4 \mathrm{yr}$. There have been no deaths of plants of known ages 5 to 8 , so the survivorship curve is flat at 0.88 across this period. Ninety plants contributed to the survivorship estimate for the 1 st yr, but only 40 to the 8 th yr survivorship value because most cohorts have not been observed that long.

Recruitment. - The size class "tiny" was designed to try to recognize seedlings. However, if presence of cotyledons is the criterion for a seedling, none were detected. It was impossible to be certain that newly found plants were not at least a year old. In the greenhouse, plants reached "small" 2 mo after germination, with the cotyledons still healthy.

Mean annual recruitment was 9.03 plants per 100 (SE 10.05) between 1981 and 1989 (Table 1). I omitted 1980 from the average because although a serious effort was made to find all Ipomoea leptophylla plants within the entire grid in 1979, 52 more plants were found in 1980, nearly doubling the population, a number so large that it suggests that some of those found in 1980 were missed in 1979. However, the size classes of plants added in 1980 were quite different from the distribution of size classes found in 1979 and resemble later 
TABLE 5.-Differences in reproductive effort by size class, Arapaho Prairie. For details of size classes, see text

\begin{tabular}{|c|c|c|c|c|c|}
\hline \multirow[b]{2}{*}{ Size } & \multicolumn{4}{|c|}{ Reproductive effort* } & \multirow{2}{*}{$\begin{array}{l}\text { Number of } \\
\text { observations }\end{array}$} \\
\hline & 0 & 1 & 2 & 3 & \\
\hline \multicolumn{6}{|c|}{ Percent of plants in each class } \\
\hline Tiny & 98.9 & $1.1 \#$ & $0 \#$ & 0 & 371 \\
\hline Small & 78.5 & $21.5 \#$ & $2.7 \#$ & $0 \#$ & 698 \\
\hline Medium & 17.3 & $82.7 \#$ & $35.2 \#$ & $5.9 \#$ & 324 \\
\hline Large & 1.7 & $98.3 \#$ & $70.7 \#$ & $30.5 \#$ & 174 \\
\hline
\end{tabular}

* $0=$ Did not flower; 1 = flowering initiated (includes 2 and 3 ); $2=$ matured at least 1 seed (includes 3); 3 = many seeds matured

\# All size classes are significantly different in frequency of flower initiation and seed production at the $1 \%$ level (chi square, $\mathrm{df}=1$ ) except tiny vs. small in the last column

years' recruits more than the population marked in 1979: plants found in 1979 were described as five tiny, 37 small, 23 medium and five large, while in 1980 the numbers in those classes, respectively, were 26,23 , two and zero. In most years the distribution of newly discovered plants was half small and half tiny. Thus it is possible that all 52 plants are actual new 1980 recruits. Since this problem cannot be solved, 1980 was omitted and the 1989 recruits (10) were added to get nine observations of annual recruitment.

Age at reproduction._Ipomoea leptophylla clearly has a minimum size for flowering (Table 5, Fig. 4). While two plants described as tiny flowered, one had been previously recorded as small, the other as medium. Of 90 plants that were first seen as tiny, none flowered while still tiny (348 plant-yr of total observations). Flowering size normally occurs somewhere at the larger end of the small size class. Of the originally tiny plants, 11 of $56(19.6 \%)$ that reached "small" during the period of observation flowered, while of the plants first seen as small, 71 of 104 (68.3\%) flowered during the period of observation. In terms of years of observation, only 119 of 662 small-class plants flowered. In contrast, 20 of 21 plants first seen as medium-sized plants flowered at least once (for the one exception there are only 2 yr of observations), and six of six large plants flowered. In the medium-size class, in 248 of $299(82.9 \%)$ plant-yr, medium plants flowered, and in 159 of $162(98.1 \%)$ plant-yr large plants flowered.

Age at first reproduction is more difficult to determine. Of 37 plants first noted as tiny and added since 1982, none have flowered (and 10 have died). Of five found as tiny in 1981, one flowered in 1986 (and not since) and three are dead. Of the 18 added in 1982, two flowered in 1988 and two (one for the second time) in 1989, and five have died. Assuming these represent seedlings, the youngest plant to flower was $5 \mathrm{yr}$ old. Of 15 survivors with at least $8 \mathrm{yr}$ of observation each, only three $(25 \%)$ have flowered, suggesting a median age at first flowering, assuming the plant survives, of at least $10 \mathrm{yr}$.

First flowering at 10 seems somewhat high. About half the recruits each year have been classified as small, and since under greenhouse conditions, seedlings can reach small within a growing season, the small class probably includes some very young plants, if not seedlings. A small plant was found in a year it also flowered in 1982, 1983 and 1988. Nine other living small plants, first seen between 1985-1989, have never flowered. Other small plants added since 1980 include nine that have never flowered, 11 that have flowered within a decade and one that died. This works out to a median age at first flowering for small plants of $6 \mathrm{yr}$. 
TABLE 6.-Relative survivorship at Kingsley Dam site

\begin{tabular}{lllllll}
\hline & \multicolumn{7}{c}{ Year } \\
\cline { 2 - 7 } Cohorts & 1977 & 1978 & 1979 & 1980 & 1981 & 1989 \\
\hline Original & 1.00 & 1.00 & 1.00 & 0.99 & 0.99 & 0.88 \\
1980 & & & & 1.00 & 1.00 & 0.52 \\
1981 & & & & 1.00 & 1.00 \\
\hline
\end{tabular}

I have never seen a greenhouse-germinated seedling flower but could not maintain these deeply rooted plants for more than $3 \mathrm{yr}$ in the greenhouse. After $7 \mathrm{yr}$ in a garden in Lincoln, three plants grown from seed are still "small" and none have flowered.

In sum, age at first flowering is estimated as $7 \mathrm{yr}$ for plants that survive. The minimum age at flowering is probably determined by size and can, under suitable conditions, be reached in $3 \mathrm{yr}$.

Reproductive success. - Since approximately $60 \%$ of the population is in tiny or small size classes (Table 2), most individuals are too small to flower (see Table 5, Fig. 4). For those that flowered, seed production was generally low. While large plants occasionally produce hundreds of seeds, this is the exception. Indeed only $12.3 \%$ of all plants that flowered could be described as producing "many" (more than 20 ) mature seeds. These are almost entirely large plants (Table 5, Fig. 4).

Flowering effort is strongly related to size $(\mathrm{F}=54.02, \mathrm{P}<0.001, \mathrm{df}=9$; SAS general linear model, SAS, 1988) and increases with size (Table 5, Fig. 4). Larger plants flowered in more years and were more likely to mature seeds successfully.

Calendar year had a significant effect on flowering effort as well $(\mathrm{F}=4.18, \mathrm{P}<0.001$, $\mathrm{df}=11$; SAS general linear model, SAS, 1988). However, substituting in the obvious rainfall variables (total precipitation for the calendar year, the previous calendar year, the same growing season, the previous growing season) produced no significant relationship except a counter-intuitive tendency for large plants to flower in years of lower rainfall ( $T=2.65$, $\mathrm{P}<0.01$, df $=1$; SAS general linear model, SAS, 1988). This is counter to the evidence at Kingsley Dam (below, and Keeler, 1980b) where better water conditions apparently provide better flowering, so I conclude that the correct variable or variables have not been tested.

\section{KINGSLEY DAM POPULATION}

Eighty-seven plants were found in 1989: 74 were present in 1977 when the site was established (Table 1). Both recruitment and deaths were virtually zero in 1977-1981, with the dramatic exception of 1980 . Of the plants marked in $1977,98.7 \%$ were still alive in 1989, compared with $50.0 \%$ of those added in 1978-1981 (Table 1, Fig. 3). This is consistent with the results at Arapaho Prairie (Fig. 3).

At Kingsley Dam, only one death was recorded for 258 plants followed from 1977 to 1981 (Table 1). Its size was not recorded. Of the 95 plants on the half of the site that survived the 1988-1989 habitat destruction, $88 \%$ were alive in 1989 , a death rate for the interval of 1.0 plant per 100 per year. The plants from the 1977 population that were missing in 1989 were (in 1981) four medium and five large. Of the 1980 cohort, those not found in 1989 were, in 1981, two tiny, three small, one medium and two large. Survivorship was 1.0 for 1977-1979, and 0.99 in 1981 . In 1989 for the 1977 cohort it was 0.88 . Survivorship of the 1980 cohort was only 0.52 , a death rate of 8.46 plants per 100 per year (Table 6).

Age distribution at Kingsley Dam varied somewhat among years (chi-square $=10.47$, 
$\mathrm{df}=3,0.025>\mathrm{P}>0.01)$ but was in all cases very different from Arapaho Prairie (e.g., 1980: chi-square $=83.2$, df $=3, P \gg 0.001$, Fig. 2 ). There were clearly fewer recruits and more large plants in the Kingsley Dam population.

Despite dramatic differences in density and age distribution, the survivorship of established plants at Kingsley Dam was similar to that at Arapaho Prairie and mortality of younger plants similarly much higher than the mortality of established plants (Fig. 4). Some mortality of large plants occurred at Kingsley Dam, as compared to none at Arapaho Prairie.

Flowering data and age at reproduction are difficult to determine for the Kingsley Dam population given the gap in observations. However, all 20 plants that were new in 1980 flowered in 1981 or 1989 , so $100 \%$ reached flowering size in 9 yr.

I attribute differences between the populations-greater density and a population with many large and very few small plants at Kingsley Dam-to the position of the Kingsley Dam population below an earthen dam holding a deep reservoir. Water relations are undoubtedly better, allowing more dense plants and more rapid growth to large size. None of the individuals should be older than $48 \mathrm{yr}$ because of the intense disturbance caused by the building of the dam.

\section{Discussion}

Population size, density and dynamics of Ipomoea leptophylla differ between Arapaho Prairie and Kingsley Dam populations. The increase of population size at Arapaho Prairie cannot be explained using demographic data although cessation of grazing by cattle seems the most probable cause; the Kingsley Dam population was stable (Fig. 1). Despite that, survivorships of established plants are similar. After 10-12 yr of observations, 118 (46.6\%) of the 253 plants marked at the start of the study were still alive, i.e., are known to have lived at least a decade. Life expectancy of seedlings in the Arapaho Prairie population is $10 \mathrm{yr}$. Death rates among large and medium plants in the period of observation were very low: approximately 0.01 per year. For these established plants, additional life expectancies are estimated at $50 \mathrm{yr}$. This will be hard to observe directly.

Projecting from the mean recruitment rate, in order to keep the population stable, plants would need to live $11.1 \mathrm{yr}$ (100 plants/9.02 deaths per year). This is so clearly incorrect (see Tables) that it reinforces the idea that recruitment was especially good in the early 1980s. The mean recruitment rate for the period studied was four times the mean death rate, but these were not statistically significantly different $(\mathrm{t}=1.86,0.1>\mathrm{P}>0.05, \mathrm{df}=$ 16 ), as can be readily observed from the between-year variation (Table 1). Birth and death rates are not distinguishable, and therefore could indicate population at equilibrium, despite the growth of the population between 1980 and 1984. At present either some estimates are sufficiently inaccurate that an incorrect distribution is generated, or, the population is nowhere near a stable state. That the population is not in a stable size distribution seems reasonable, however flawed the estimate. Consistent with interpreting the population as deviating from a stable size distribution is the projection from the stable size of population growth of about $2 \%$ a year, which is lower than the observed growth rate for the decade (Table 1, Figs. 1, 2).

Another approach to estimating lifespan is from the rate of progression through size classes. Plants spent at least $5 \mathrm{yr}$ per size class at Arapaho Prairie (e.g., no plant increased more than three size classes in $10 \mathrm{yr}$ ); large plants must thus be at least $20 \mathrm{yr}$ old. At Kingsley Dam growth was faster, and large was reached within the $12 \mathrm{yr}$ of observation. More available moisture is probably responsible.

Plants were observed to emerge after being underground 1-2 yr. Given Ipomoea lepto- 
phylla's tumbleweeding habit and the strong prairie winds, it is possible some of the plants may not have been dormant but that the aboveground plant blew away before the census was taken, but I do not believe that explains all eight cases. Remaining underground has been observed for other prairie forbs (A. Antlfinger, pers. comm.; M. Fritz, pers. comm.; R. B. Kaul, pers. comm.).

Causes of death remain obscure. Dehydration, perhaps exacerbated by competition from surrounding species, probably causes the death of tiny and small plants, but I cannot prove it. "Accidents," e.g., erosion of the site, caused two deaths and fungal infection is implicated in one. Herbivory does not appear to be a major problem for adult plants as they are welldefended by alkaloids (Steward and Keeler, 1988) and even when cattle are present they avoid the leaves (Keeler, 1980b). It is the reproductive phase that is severely affected by biotic interactions: grasshoppers damage a substantial proportion of flowers and bruchids can destroy $100 \%$ of a seed crop (Keeler, 1980b).

Age at first reproduction is estimated at $6 \mathrm{yr}$ for Arapaho Prairie. This is consistent with a long life expectancy. Many perennial herbs have long juvenile periods (Harper, 1971; Meagher, 1981, 1982; Kawano et al., 1982; Inge and Tamm, 1988).

The percent of years in which the plant flowered and percent of years in which a plant successfully set seed increased with size. This is probably the most common pattern for plants (Harper, 1971; Kawano et al., 1982; Meagher and Antonovics, 1982). While large plants made a disproportionate contribution to seed production, the low mortality across established plants suggests that a relatively even contribution by different individuals is possible as younger individuals grow into larger size classes. At present there has been insufficient time to determine whether turnover among large individuals is regular, giving all adults an opportunity to be good seed producers, or whether some live significantly longer or reach demonstrably greater sizes than others.

That plants weighing no more than $5 \mathrm{~kg}$ can be shown to live as long as forest dominants is not unexpected but provides substance for the view that prairie dynamics may be seen in terms of centuries, not years. Comparable ages are inferred for forest understory herbs such as Chamaelirium (Meagher and Antonovics, 1982), Arisema (Bierzychudek, 1981), Hepatica (Inge and Tamm, 1985, 1988) and montane species such as Frasera (Inouye and Taylor, 1980). In prairie ecosystems, few studies exist. Weller (1985) studied Lithospermum caroliniense (Boraginaceae) on the dunes around Lake Michigan and concluded from observations and experimental data that life expectancies approached $100 \mathrm{yr}$. Lithospermum is abundant in the sandhills prairie studied here (Keeler et al., 1980) and plant sizes suggest even greater ages than the dune populations (Weller, pers. comm.). Antlfinger (pers. comm.) has $6 \mathrm{yr}$ of demographic data on Spiranthes cernua (Orchidaceae) in tallgrass prairie and projects lifespans in excess of $30 \mathrm{yr}$.

On the other hand, sandhills prairies have an abundance of short-lived herbaceous perennials (Pool, 1914; Keeler et al., 1980; Keeler, 1987; Louda et al., 1990).

Observations of the seed to seedling phase are conspicuously lacking. Despite repeated searching, no plants with cotyledons were seen in the field. In the greenhouse scarified or thoroughly imbibed seeds germinate promptly, although leaf damage from the seed coat is common. An experimental planting of seeds to determine field emergence conditions did not yield any seedlings in $7 \mathrm{yr}$ and was terminated. I hypothesize that some years are needed to wear down the seed coat enough for germination. Seedlings undoubtedly also need a wet spring in order to grow deep enough roots to withstand summer drought. The short growing season of the adults (mid-June to early September) suggests limited frost tolerance, so seedlings may also succumb to late frosts. 
Only upon reaching large sizes do plants flower regularly. This and the tendency to abort flowers and fruit in bad years suggest a cost of reproduction. Since larger plants flower regularly, apparently they generate adequate photosynthate to support flowering on an ad hoc basis and do not commit energy to flowering unless enough resources have already been sequestered for winter survival.

Ipomoea leptophylla is clearly a stress tolerator in the terminology of Grime (1979), a plant with a very conservative growth and reproduction pattern. Factors that limit these plants to a sparse distribution are not obvious. One is seedling mortality. The relatively low rate and number of seeds produced probably contribute, especially given the losses to bruchids, which generally exceed $50 \%$. This trades off against the longevity of the seeds: a reasonable number are presumably ungerminated in the soil given their longevity under laboratory conditions.

Comparison with the stable and dense population at Kingsley Dam, however, suggests that (1) the number of sites in which germination and establishment can be successful may be fewer at Arapaho Prairie, specifically because of less reliable water availability and (2) relaxation of grazing at Arapaho Prairie created conditions for plant establishment which are apparently no longer available. While much still needs to be done to understand the longevities of this species, it appears from present data that equilibrium, in the sense that births roughly balance deaths, can be attained in a few years, despite the very long lives of the individuals. Shifts will of course have consequences that carry through an entire cohort, however rapidly a new equilibrium is attained. Thus, the impact of looking at only a few years of an Ipomoea leptophylla population will lead to different degrees of imprecision depending on the question (cf., Likens, 1989). As this is an unimportant herb (either as a dominant, keystone species, or economically important plant), the fates of particular individuals on the age distribution are unlikely to be of general concern. Age distributions take decades to equilibrate, and so probably never do. However in terms of equilibrial abundance in its community, it does appear to reach stable numbers in response to prairie management in a decade, and in that context, its long lifespan may be disregarded. These conclusions are of course, only provisional and the study is continuing.

One obvious outcome of longevity is on the individual's interspecific relationships. Ants feeding at Ipomoea leptophylla extrafloral nectaries have an interaction that may last many years (Keeler, 1980b). That is especially true for the ant Formica obscuripes, which itself has long-lived colonies: my notes on one colony within the Arapaho site go back $7 \mathrm{yr}$ and it is probably older than that. European studies of Formica species indicate colonies can be over $100 \mathrm{yr}$ old (Wilson, 1971). Likewise, organisms associated with particular plants could represent long lineages on the same host. While that seems unlikely for a relatively strong flier like the bruchid beetle Megacerus, long interactions are likely for the fungus Albugo. Ipomoea leptophylla is not an abundant resource, and it has excellent chemical defenses (Steward and Keeler, 1988), but its leaves provide a stable and predictable resource in a habitat of high climatic variation. Flower and seed availability vary considerably more between years and ought to cause occasional crashes of the bruchid seed predator, pollencollecting anthophorid bees and a flower-eating lepidopteran larva (Keeler, 1980b). Perhaps the largest adults, by flowering in most years, provide sufficient resources to sustain the populations of those dependent insects.

Acknowledgments. - I thank G. Drohman for growing a variety of seedlings, J. Steward for investigations of related biological problems, B. Kwankin, K. Anderson and K. Taylor for help with data collection and Cedar Point Biological Station for logistical help. D. Marx and D. S. Stephens provided invaluable analytical support. I thank L. S. Vescio for instruction on a variety of programs. 